\title{
ANALYSIS AND COMPARISON OF THICKNESS AND BENDING MEASUREMENTS FROM FABRIC TOUCH TESTER (FTT) AND STANDARD METHODS
}

\author{
Atiyyah Binti Haji Musa ${ }^{1,2 *}$, Benny Malengier ${ }^{1}$, Simona Vasile ${ }^{3}$, Lieva Van Langenhove ${ }^{1}$, Alexandra De Raeve $^{3}$
}

${ }^{1}$ Ghent University, Department of Materials, Textiles and Chemical Engineering, Centre for Textile Science and Engineering, Technologiepark 907, 9052 Zwijnaarde (Gent), Belgium

2Universiti Teknologi MARA Cawangan Negeri Sembilan, Kampus Kuala Pilah, 72000 Kuala Pilah, Negeri Sembilan, Malaysia.

${ }^{3}$ University College Ghent, Faculty of Science and Technology, Department of Fashion, Textiles and Wood Technology/ FTI Lab, Buchtenstraat 11, 9051 Gent, Belgium.

*corresponding author e-mail: Atiyyah.BintiHajiMusa@UGent.be

\begin{abstract}
:
Fabric Touch Tester (FTT) is a relatively new device from SDL Atlas to determine touch properties of fabrics. It simultaneously measures 13 touch-related fabric physical properties in four modules that include bending and thickness measurements. This study aims to comparatively analyze the thickness and bending measurements made by the FTT and the common standard methods used in the textile industry. The results obtained with the FTT for 11 different fabrics were compared with that of standard methods. Despite the different measurement principle, a good correlation was found between the two methods used for the assessment of thickness and bending. As FTT is a new tool for textile comfort measurement and no standard yet exists, these findings are essential to determine the reliability of the measurements and how they relate to the well-established standard methods.
\end{abstract}

\section{Keywords:}

fabric touch tester, thickness, bending, standard method

\section{Introduction}

Fabric comfort is a globally discussed issue as humans are dealing with fabrics every single day. Since everyone perceives comfort differently, the result is subjective and different for each individual. Hence, many attempts have been made in order to communicate about this subject objectively, so that everyone would understand the same common language of fabric comfort. The efforts involved research to understand the way comfort is perceived,[1-3] to develop equipment for the estimation of hand related features,[4-6] and to model the skintextile interaction.[7-9] Skin-textile interaction is important as it forms the basis of how comfort is perceived by humans. $[1,10]$

A number of devices were developed to be able to objectively measure textile comfort. Amongst many research studies conducted, Kawabata (KES-F)[11-13] and Fabric Assurance by Simple Testing (SiroFAST)[13,14] are systems that are well accepted for this purpose. However, these systems require several different testing apparatuses to measure all touch modules, and also require much time and material for testing. Hence, recently SDL Atlas has developed a new device called the fabric touch tester (FTT) in collaboration with a team of researchers from The Hong Kong Polytechnic University, which is claimed to be able to measure 13 touch indices simultaneously in less than five minutes per sample (see Figure 1). The FTT has four modules which are integrated in one single equipment and operated at the same time: compression, thermal, bending and surface module. All the indices are then computed to yield the primary hand value, which consists of smoothness, softness and warmness, total hand and total touch. Table 1 lists the indices measured in FTT.

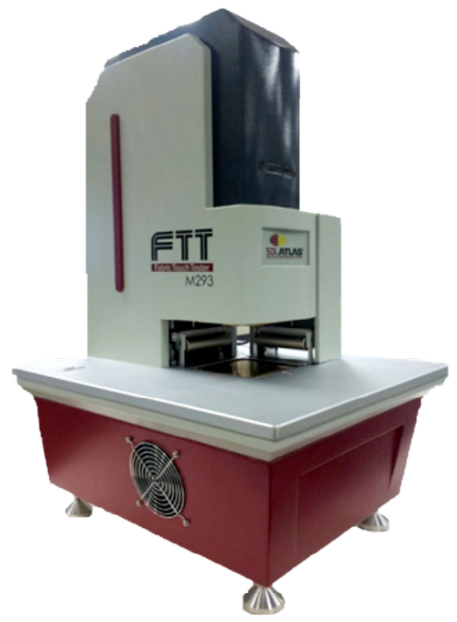

Figure 1. Fabric touch tester

There is limited work pertaining to the use of this device as it has been introduced relatively recent in the market. The study by Hu et al. from The Hong Kong Polytechnic University using the prototype version of the FTT found that this device can be used to evaluate fundamental fabric mechanical and thermal properties. It is also able to predict fabric-skin touch sensations under non-sweating conditions like smoothness, softness, prickliness, warmth and dampness.[15] It is further reported that the stiffness measurement of FTT is significantly correlated with subjective assessment and KES.[16] In 2014, the device was improved with some refinement in indices by Liao et al.[17] They investigated the effects of thermal perceptions on the tactile perceptions and found correlations between FTT results and subjective evaluation scores. A study by the same team about psychophysical relations between various conditions of fabric thermal-tactile properties and psychological 
Table 1. FTT indices

\begin{tabular}{|c|c|c|c|c|c|c|}
\hline Item & $\begin{array}{l}\text { Fabric } \\
\text { Property }\end{array}$ & Index & Description & $\begin{array}{l}\text { Unit given } \\
\text { by FTT } \\
\text { software }\end{array}$ & SI unit & Usual interpretations \\
\hline 1 & \multirow[b]{2}{*}{ Bending } & BAR & Bending Average Rigidity & gf mm rad $\mathrm{mm}^{-1}$ & $\mathrm{~N} \mathrm{~m} \mathrm{rad}-1$ & Force needed to bend per radian \\
\hline 2 & & BW & Bending Work & gf $\mathrm{mm}$ rad & $\mathrm{N}$ m rad & $\begin{array}{l}\text { Work needed to bend the } \\
\text { specimen }\end{array}$ \\
\hline 3 & $\begin{array}{l}\text { Surface } \\
\text { friction }\end{array}$ & SFC & $\begin{array}{l}\text { Surface Friction } \\
\text { Coefficient }\end{array}$ & - & - & $\begin{array}{l}\text { Friction coefficient on surface } \\
\text { with ribbed metal plate }\end{array}$ \\
\hline 4 & \multirow{2}{*}{$\begin{array}{l}\text { Surface } \\
\text { roughness }\end{array}$} & SRA & $\begin{array}{c}\text { Surface Roughness } \\
\text { Amplitude }\end{array}$ & $\mu \mathrm{m}$ & $\mathrm{m}$ & $\begin{array}{l}\text { Roughness irregular wave } \\
\text { amplitude }\end{array}$ \\
\hline 5 & & SRW & $\begin{array}{c}\text { Surface Roughness } \\
\text { Wavelength }\end{array}$ & $\mathrm{mm}$ & $\mathrm{m}$ & $\begin{array}{c}\text { Roughness irregular wave } \\
\text { wavelength }\end{array}$ \\
\hline 6 & \multirow{5}{*}{ Compression } & CW & Compression Work & $\mathrm{gf} \mathrm{mm}$ & $\mathrm{N} \mathrm{m}$ & $\begin{array}{l}\text { Work needed to compress the } \\
\text { specimen }\end{array}$ \\
\hline 7 & & CRR & $\begin{array}{c}\text { Compression Recovery } \\
\text { Rate }\end{array}$ & - & - & $\begin{array}{l}\text { Percentage of thickness } \\
\text { changes after compressed }\end{array}$ \\
\hline 8 & & CAR & $\begin{array}{l}\text { Compression Average } \\
\text { Rigidity }\end{array}$ & gf $\mathrm{mm}^{-3}$ & $\mathrm{~N} \mathrm{~m}^{-3}$ & $\begin{array}{l}\text { Forces needed to compress per } \\
\qquad \mathrm{mm}\end{array}$ \\
\hline 9 & & RAR & $\begin{array}{l}\text { Recovery Average } \\
\text { Rigidity }\end{array}$ & gf $\mathrm{mm}^{-3}$ & $\mathrm{~N} \mathrm{~m}^{-3}$ & $\begin{array}{l}\text { Forces reflected when recovery } \\
\text { per } \mathrm{mm}\end{array}$ \\
\hline 10 & & $\mathrm{~T}$ & Thickness & $\mathrm{mm}$ & $\mathrm{m}$ & Thickness of the materials \\
\hline 11 & \multirow{3}{*}{$\begin{array}{l}\text { Thermal } \\
\text { conductivity }\end{array}$} & TCC & $\begin{array}{l}\text { Thermal Conductivity } \\
\text { under Compression }\end{array}$ & $\begin{array}{c}10^{-3} \mathrm{~W} \mathrm{~m}^{-1} \\
{ }^{\circ} \mathrm{C}^{-1}\end{array}$ & $\mathrm{~W} \mathrm{~m}^{-1}{ }^{\circ} \mathrm{C}^{-1}$ & $\begin{array}{l}\text { Energy transmitted per degree } \\
\text { per } \mathrm{m} \text { per second when the } \\
\text { specimen is under compression }\end{array}$ \\
\hline 12 & & TCR & $\begin{array}{l}\text { Thermal Conductivity } \\
\text { under Recovery }\end{array}$ & $\begin{array}{c}10^{-3} \mathrm{~W} \mathrm{~m}^{-1} \\
{ }^{\circ} \mathrm{C}^{-1}\end{array}$ & $\mathrm{~W} \mathrm{~m}^{-1}{ }^{\circ} \mathrm{C}^{-1}$ & $\begin{array}{l}\text { Energy transmitted per degree } \\
\text { per } m \text { per second when the } \\
\text { specimen recovers }\end{array}$ \\
\hline 13 & & Qmax & Thermal Maximum Flux & $\mathrm{W} \mathrm{mm^{-2 }}$ & $W \mathrm{~m}^{-2}$ & $\begin{array}{l}\text { Maximum energy transmitted } \\
\text { during compression }\end{array}$ \\
\hline
\end{tabular}

touch perceptions utilized the FTT device to obtain physical data. The results imply that both thermal and tactile physical stimuli affect the touch sensation simultaneously.[18] An on-going project named Touché, funded by the European Commission, aims to develop a set of fast, cost-effective and reliable objective test methods and improve textile skin models for the assessment of Hand of Textiles (HoT) and Fabric Feel (FF). This research project employs FTT for the objective measurements.[19]

The first property studied in this paper is thickness. It is a common physical property evaluated in many fields including textiles. In textiles, thickness can influence the comfort sensation, as it is related to heat dissipation and air permeability through fabrics.[20, 21] On the other hand, bending behavior that is the second property for this study, reflects the stiffness property of the textiles, which also influences the smoothness sensation, thus would also contribute to the overall comfort perceived by humans. It is one of the basic parameters which are decisive for sensorial comfort along with compression, elongation, dimensional stability, etc.[22,23]

This paper uses the FTT, but focuses only on thickness measurement and the bending module. We compared results obtained from the FTT with the existing techniques as described in standard methods. The findings from this study serve as an indicator to check for the reliability and comparability of this equipment as it would determine how far the singular FTT results can be used to replace the current standard techniques to draw conclusions for thickness and bending properties.

\section{Materials and methods}

A total of 11 fabrics were prepared to be tested using FTT and standard methods. The fabrics have different fiber compositions and some of them are imparted with water and oil repellent finish. Table 2 shows the details of the fabrics.

For FTT, each fabric was cut in an $\mathrm{L}$ shape $(31 \times 31 \mathrm{~cm})$ (see Figure 2) as per guidelines provided by the machine manufacturer.[24] The sample was placed on the bottom plate of the FTT instrument with two legs of the $L$ shape placed on adjacent platforms within the device. The upper plate was setup with $10^{\circ} \mathrm{C}$ higher temperature than the bottom plate to mimic the temperature difference between skin and textiles. When the test starts, the upper plate moves gradually downward 
Table 2. Fabrics characteristics

\begin{tabular}{|c|c|c|c|c|c|c|c|}
\hline Fabric & Fiber composition & $\begin{array}{l}\text { Weight } \\
\left(\mathrm{g} / \mathrm{m}^{2}\right)\end{array}$ & $\begin{array}{l}\text { Warp } \\
\text { linear } \\
\text { density } \\
\text { (tex) }\end{array}$ & $\begin{array}{l}\text { Weft } \\
\text { linear } \\
\text { density } \\
\text { (tex) }\end{array}$ & $\begin{array}{l}\text { Fabric } \\
\text { density } \\
(\text { per cm) }\end{array}$ & $\begin{array}{c}\text { Fabric } \\
\text { construction }\end{array}$ & Finishes \\
\hline$A$ & $50 \%$ Nomex, $50 \%$ viscose & 269.18 & $22 / 2$ & $22 / 2$ & $32 \times 22$ & Twill 2/1 & $\begin{array}{l}\text { Water and oil } \\
\text { repellent }\end{array}$ \\
\hline B & $50 \%$ Kermel, $50 \%$ viscose & 253.44 & $22 / 2$ & $22 / 2$ & $32 \times 22$ & Twill 2/1 & $\begin{array}{l}\text { Water and oil } \\
\text { repellent }\end{array}$ \\
\hline $\mathrm{C}$ & $70 \%$ Kermel, $30 \%$ viscose & 228.74 & $20 / 2$ & $19 / 2$ & $32 \times 22$ & Twill 2/1 & $\begin{array}{l}\text { Water and oil } \\
\text { repellent }\end{array}$ \\
\hline $\mathrm{D}$ & $50 \%$ Nomex, $50 \%$ viscose & 253.56 & $22 / 2$ & $22 / 2$ & $32 \times 22$ & Twill 2/1 & - \\
\hline$E$ & $69 \%$ Nomex, $31 \%$ wool & 242.72 & $17 / 2$ & $\begin{array}{l}18 / 2 \\
13 / 4\end{array}$ & $32 \times 22$ & $\begin{array}{l}\text { Combination } \\
\text { twills }\end{array}$ & - \\
\hline $\mathrm{F}$ & $\begin{array}{l}50 \% \text { M-Aramid, } 50 \% \text { Lenzing } \\
\text { FR (flame retardant) }\end{array}$ & 268.64 & $24 / 2$ & $24 / 2$ & $32 \times 22$ & Twill 2/1 & - \\
\hline G & $\begin{array}{c}50 \% \text { M-Aramid, } 48 \% \text { Lenzing } \\
\text { FR (flame retardant), } 2 \% \\
\text { carbon-based fibers }\end{array}$ & 262.82 & $23 / 2$ & $23 / 2$ & $32 \times 22$ & Twill 2/1 & - \\
\hline $\mathrm{H}$ & $\begin{array}{c}70 \% \text { M-Aramid dope dyed, } \\
30 \% \text { viscose }\end{array}$ & 220.08 & $20 / 2$ & $20 / 2$ & $32 \times 22$ & Twill 2/1 & $\begin{array}{l}\text { Water and oil } \\
\text { repellent }\end{array}$ \\
\hline 1 & $100 \%$ polyester & 293.86 & $50 / 2$ & $20 / 1$ & $36 \times 25$ & Twill 4/1 & - \\
\hline $\mathrm{J}$ & $100 \%$ cotton & 281.88 & $50 / 2$ & $20 / 1$ & $36 \times 25$ & Twill $1 / 4$ & \\
\hline $\mathrm{K}$ & $50 \%$ cotton, $50 \%$ polyester & 202.72 & $30 / 1$ & $30 / 1$ & $12 \times 16$ & $\begin{array}{c}\text { Knitted - } \\
\text { single jersey }\end{array}$ & - \\
\hline
\end{tabular}

and touches the fabric. The fabric is brought further downward by both plates and after several seconds, they go back to the initial position (see Figure 3). As the test was running, the compression and bending sensors, concurrently with other sensors, were fed with the input from the tested fabrics, and the readings were computed through the FTT software provided by the manufacturer. This is done for the inside and outside of the fabric in warp and weft directions. Ten specimens were tested for each of the 11 fabrics.

By using a thickness gauge, the thickness of the fabrics was measured according to the ISO 5084:1996 (E), standard

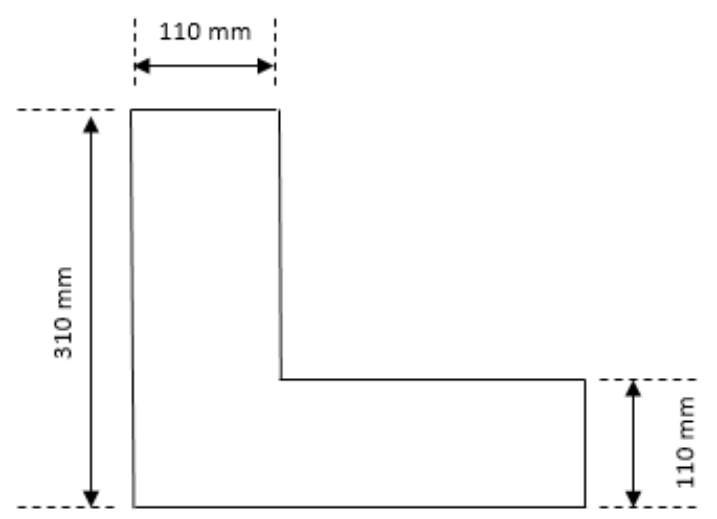

Figure 2. Fabric sample dimension method for determination of thickness of textiles.[25] Following the standard, the fabrics were placed in between the circular presser foot and the reference plate of the thickness tester. The area of the presser foot is approximately $2000 \mathrm{~mm}^{2}$ with $1 \mathrm{kPa}$ pressure. Then, the gauge reading was taken after 30 seconds at different areas on the samples for at least five times. After that, the mean was calculated to be used in the analysis.

Bending measurement was performed based on BS 3356-1990 standard.[26] For this test, rectangular samples measuring 2.5 $X 20 \mathrm{~cm}$ were prepared so that the length is parallel to the direction to be tested. Five warp and five weft pieces were tested for each type of fabric in this experiment. The samples were glided on the fixed-angle flexometer, which is based on the cantilever principle. According to Pierce,[27] bending length $C$ is the length of rectangular strip of material that will bend under

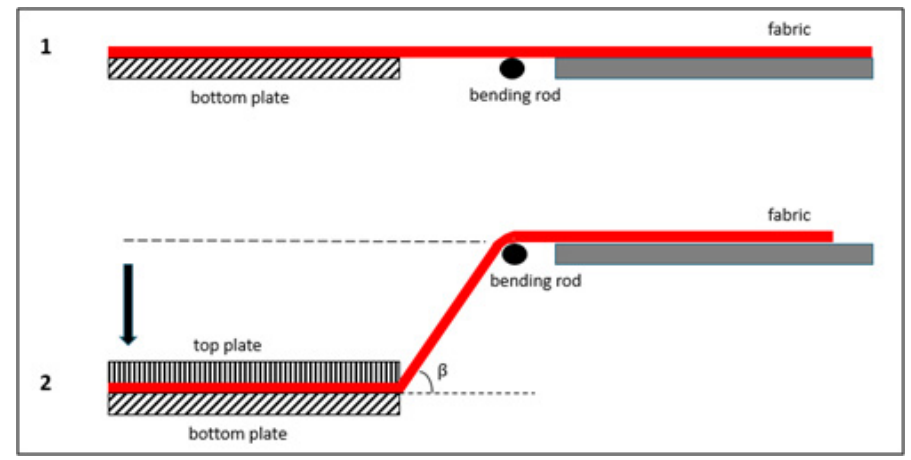

Figure 3. Schematic diagram of bending motion in FTT 
its own mass to an angle of $7.1^{\circ}$. For ease of measurement, this method uses the cantilever length corresponding to the angular deflection $\theta=41.5^{\circ}$, so that the bending length is half of the cantilever length, as shown in the following equation. Hence, the bending length was read from the ruler when the tip of the sample touched the red line of $41.5^{\circ}$ on the apparatus (see Figure 4). The higher the bending length, the stiffer the fabric is.

Bending length $C$ is given by the calculation (1):

$$
\mathrm{C}=l\left(\frac{\cos (\theta / 2)}{8 \tan \theta}\right)^{1 / 3}=l / 2 \text {, }
$$

where we used $\theta=41.5^{\circ}$, and $I$ is the sample overhanging length at that angle.

By using the appropriate mean value, the flexural rigidity $G$ of the fabrics is determined in the standard using formula (2):

$$
\mathrm{G}=0.10 \mathrm{M} \mathrm{C}^{3}(\mathrm{mg} \mathrm{cm})
$$

where $C$ is the bending length $(\mathrm{cm})$, and $M$ is the fabric mass $(\mathrm{g} /$ $\mathrm{m}^{2}$ ). In the standard method, the unit is not given in a standard unit (SI). With SI units, the flexural rigidity of a plate is the force couple $(\mathrm{Nm})$ required per width $(\mathrm{m})$ to bend the plate in one unit of curvature $(1 / \mathrm{m})$, and hence, has the general unit for a plate of $\mathrm{Nm}$.

In FTT, thickness is part of the compression module, where the value is recorded together with the pressure exerted when the fabric is sandwiched between upper and lower plates. The compression sensor measured the compression forces and at the same time, the laser distance sensor recorded the distance

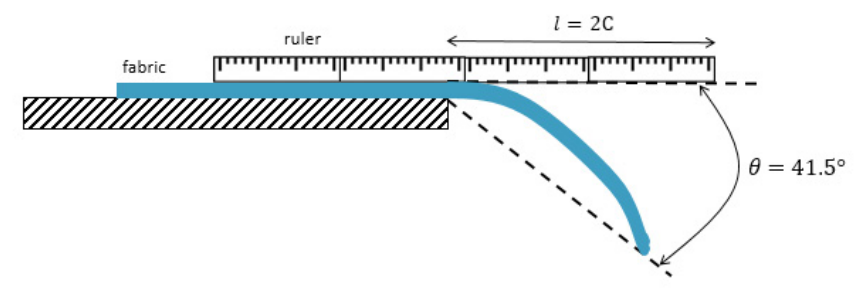

Figure 4. Schematic diagram of bending test according to BS 33561990 standard method

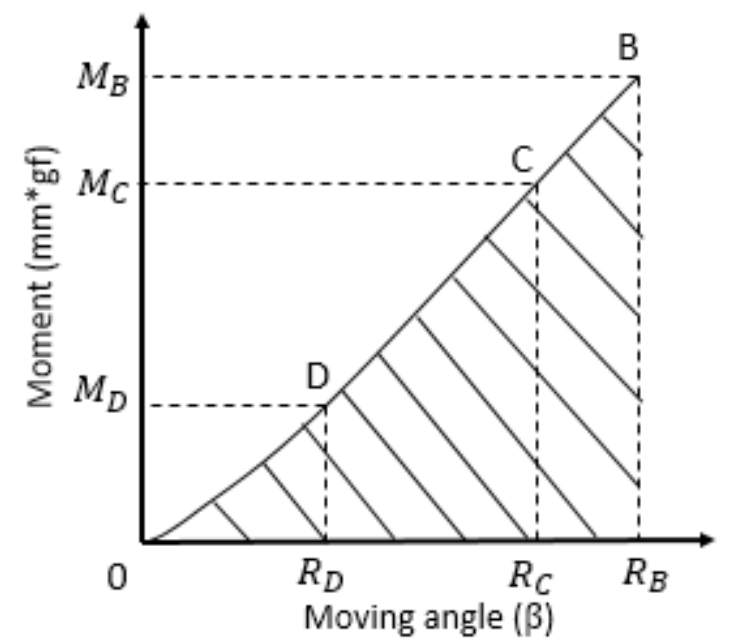

Figure 5. Calculation diagram of BAR and BW indices between the two plates, which were then converted to sample thickness. The reading for thickness is given when the pressure is at $4.018 \mathrm{kPa}[15]$, whereas ISO 5084: 1996 (E) applies a specified pressure of $1.0 \pm 0.01 \mathrm{kPa}$ when compressing the samples, and thus, the thickness value is read from the thickness gauge when that pressure is reached.[25]

Bending in the FTT is expressed as bending work (BW) and bending average rigidity (BAR), which are both categorized with bending module. The bending rods in FTT are placed at the same level as the lower plate and can be pushed downwards to exert a bending force during the test (see Figure 3 ). Force sensors are positioned under the bending rods to record the dynamic bending forces, which are then converted into a bending moment. A graph of the moving bending angle of the sample (which has maximum value of 1.05 radian) versus bending moment ( $\mathrm{gf} \mathrm{mm}$ ) is obtained (see Figure 5), and the integral of this curve over all angles is reported as the BW parameter, while the slope of this curve for the center $60 \%$ of the bending moment is reported as the BAR parameter.[17] The main interface of the FTT software is as shown in Figure 6. This instrument takes angle dependent bending into account, while the standard method BS 3356-1990 only measures bending at $41.5^{\circ}$ or 0.724 rad in one direction of bending, which means the fabric bends under its own weight. The formulae for BAR (unit $\mathrm{gf} \mathrm{mm} / \mathrm{rad}$ ) and BW (unit $\mathrm{gf} \mathrm{mm}$ rad) are as follow (3);

$$
\begin{aligned}
& B A R=\frac{M\left(R_{C}\right)-M\left(R_{D}\right)}{R_{C}-R_{D}}, \\
& B W=\int_{0}^{R_{B}} M(\beta) d \beta,
\end{aligned}
$$

where $M(\beta)$ is the measured bending moment at angle $\beta$ for the sample of $11 \mathrm{~cm}$ width, and $R_{D}$ to $R_{C}$ are the angle values at $20 \%$ and $80 \%$ of maximum bending moment $M_{B}$ obtained at maximum angle $R_{B}=1.05$ radian.

It is important to note that all the samples were conditioned at $20^{\circ} \mathrm{C} \pm 2{ }^{\circ} \mathrm{C}$ and relative humidity of $65 \% \pm 4 \%$ for at least 24 hours prior testing. The results obtained from the thickness and bending test were then compared and analyzed with FTT results.

\section{Results and discussion}

FTT software computes the results for 13 indices (as displayed in Table 1) simultaneously, plus the handle value of the fabrics. However, for this study, only the indices related to thickness and bending were emphasized. FTT gives thickness results in millimeter $(\mathrm{mm})$. Similarly, the standard method yields the value in the same unit although the measurement methods were different. On the other hand, the two FTT indices related to bending; BAR and BW, have the units of $\mathrm{Nm} \mathrm{rad}^{-1}$ and $\mathrm{Nm}$ rad respectively, in contrast with the unit given by the standard method, which is in centimeter $(\mathrm{cm})$ for bending length $C$ and $\mathrm{mg} \mathrm{cm}$ for flexural rigidity $\mathrm{G}$. Table 3 shows the results from FTT and the thickness and bending test from standard methods as well. 
FTT measures the outside and inside of the sample and gives two distinct readings for thickness even for the same piece of fabric sample. However, statistical analysis confirms that there are no significant differences for both sides thickness reading of a specific fabric type ( $p$-value $>0.05$ ). Hence, the values for inside and outside are averaged out for the correlation analysis. A t-test is conducted to examine whether the measurements are different between both methods and it shows significant differences ( $p$-value $<0.05$ ) between the thickness measured by FTT and the standard method. Correlation analysis of the measurements also yields the result that they are however correlated to each other (Pearson's correlation coefficient $=$ 0.97).

In Figure 7, the thickness measurement of FTT and standard method are displayed in a scatter diagram with a regression line drawn on it. It shows that both measurements are highly positively correlated in linear relationship and the line fits most of the data $\left(R^{2}=0.95\right)$. The differences in readings for FTT and standard method ISO 5084: 1996 (E) can be the results of the different pressure used over a different contact area. The pressure is $1 \mathrm{kPa}$ for the standard method and $4.018 \mathrm{kPa}$ in FTT, which interacts differently with the compression rigidity of the fabrics. Due to the higher pressure on the sample and the bigger surface area during compression in FTT, the readings given are consistently lower than that of the standard method. However, the intercept at $y=-0.2341$ is unexpected. Although the FTT does not export the full measurement, it is possible in the interface to consult this data. Hence, we investigated the measurement data for compression as given in Figure 8, which shows a measurement of sample K (FTT thickness 0.67 , BS thickness 0.84 ). From the figure, it can be clearly seen how the

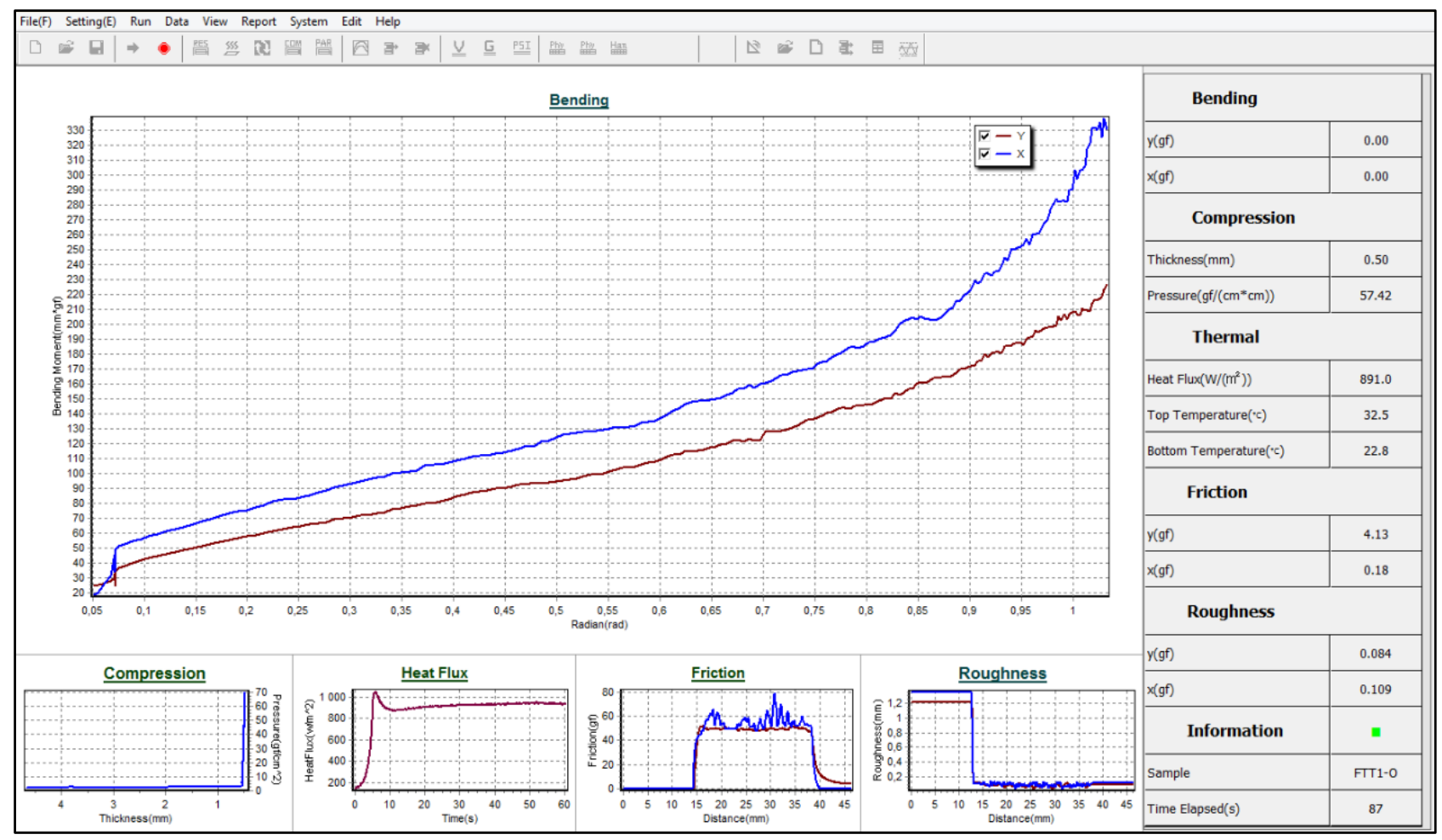

Figure 6. An example of FTT main interface during measurement

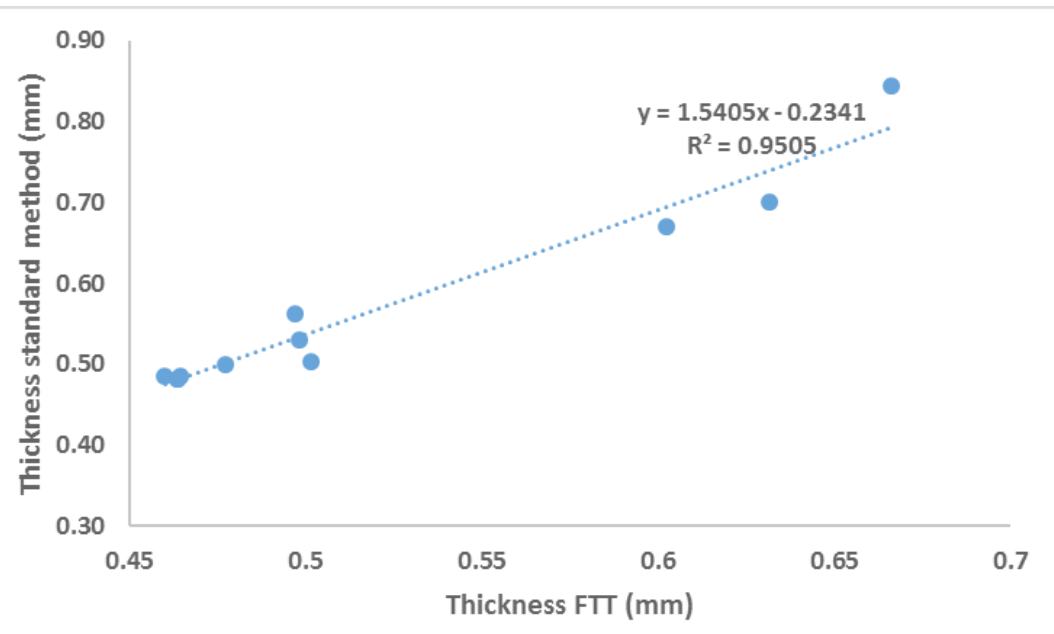

Figure 7. Correlation between thickness FTT and thickness standard method 
thickness value reduces under increasing pressure. Focusing on the lower pressure, it is observed that the compression pressure starts to increase around 0.85 , consistent with the standard method value. Hence, careful analysis of the data should allow us to obtain thickness values closer to the $1 \mathrm{kPa}$ (about $10 \mathrm{gf} / \mathrm{cm}^{2}$ ) of the standard. However, it is impossible to obtain this dataset from the FTT software; hence, the thickness data of the lower pressure is not accessible for further exploration. The graphical data does show that when there is no contact yet with the fabric, the compression pressure is already over $0.25 \mathrm{kPa}$, indicating that the sensor used has an accuracy around $0.25 \mathrm{kPa}$ which might explain why $4.018 \mathrm{kPa}$ is used to set the FTT thickness.

Since the FTT is not provided with a zero-point thickness calibration, an investigation is done to determine whether there is any shift in the zero-point of the FTT. First, the FTT was run without any sample on it in order to see what are the values it picks up. Next, we measured several rigid bodies for which FTT is expected to give consistent values. Results from this showed that the FTT picks up $0 \mathrm{~mm}$ thickness when no sample was present and a very small deviation of $0.01 \mathrm{~mm}$ was observed for a $1 \mathrm{~mm}$ thick rigid plate. This is as expected, as for a rigid plate, no thickness changes are expected at $1 \mathrm{kPa}$ versus $4.018 \mathrm{kPa}$. Although the deviation is very small, textiles cannot be expected to behave the same way as the factors like hairiness, and surface contour would give different impact to the measurement. Hence, we conclude that there is no zero shift in the FTT, provided the operator regularly performs a thickness calibration with rigid bodies, as we did here. In our experience, deviations in thickness measurement $>0.02 \mathrm{~mm}$ on rigid bodies with the FTT can be resolved by extensive cleaning of the lower and upper FTT plates.

However, despite the differences in the measurement methods, a very good correlation is found for the selected samples.
Although the found regression line will not be universal for all fabrics, it will instead depend on the compression rigidity. Hence, for fabrics outside the tested range of approximately $0.45-0.85 \mathrm{~mm}$ thickness or with different compression rigidity, a new regression curve is needed before solely depending on the FTT for thickness measurements and correcting for the higher pressure applied.

The bending module in FTT computes the input for bending average rigidity (BAR) and bending work (BW) indices in warp and weft directions, also from outside and inside of the fabric. These two indices were compared with the bending length $\mathrm{C}$ and flexural rigidity $\mathrm{G}$ obtained from the standard method measurement, as well as the MC and MCC value. The MC index is obtained by multiplying the fabric mass $M$ with the bending length $C$, and for the MCC index, the mass is multiplied by its squared bending length. These two indices, $M C$ and $M C C$ are derivatives from $\mathrm{G}\left(=0.1 \mathrm{MC}^{3}\right)$, included to test any other possible relationship that could be linked to bending.

The Pearson correlation or the $r$ value indicates the strength of the interaction between the analyzed indices. As can be seen in Table 4 , the $r$ values ranged from 0.77 to nearly 1 for all the indices compared. It is no doubt that BAR is highly correlated with BW, where a high BAR would make a high BW in a linear way relationship. Looking at the measurement principle of both FTT and standard methods, huge differences can be seen where FTT measures the moment or work needed to bend one radian of sample, which means the more work or moment needed to bend the sample, the stiffer the fabric is. Instead, flexural rigidity $G$, in the standard method, measures the force needed to bend the sample in one unit curvature and $\mathrm{C}$ or bending length is half the overhanging length of the sample, when it bends down under its own mass during the experiment. In the FTT, the sample bends over a thin rod, while the angle of bending increases as the FTT plates go down, while the

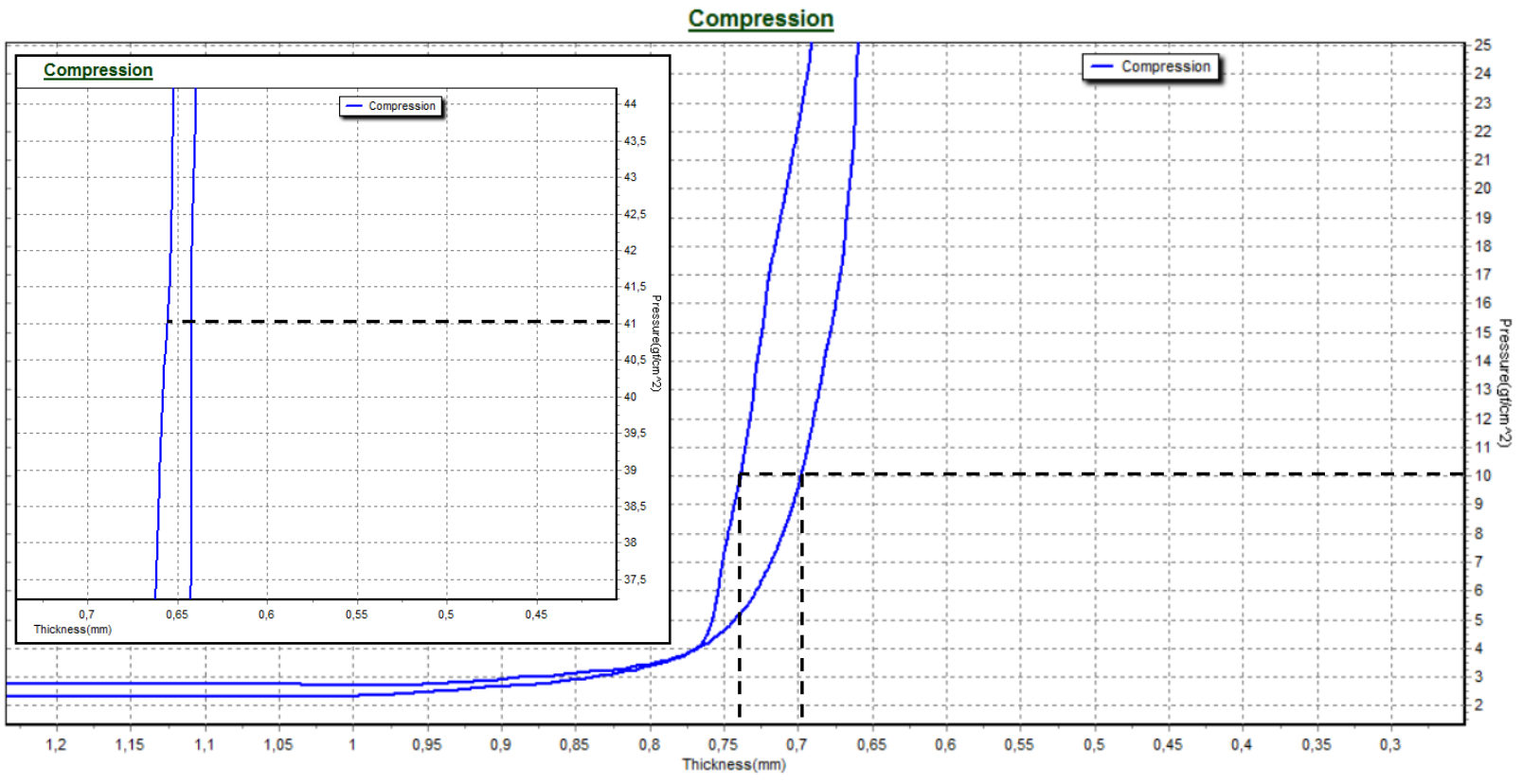

Figure 8. Measurement data of compression for sample K (screenshot from FTT software) 


\begin{tabular}{|c|c|c|c|c|c|c|c|c|c|c|c|c|c|c|c|c|c|c|c|c|c|c|c|}
\hline \multirow{4}{*}{ 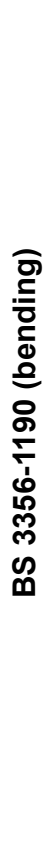 } & 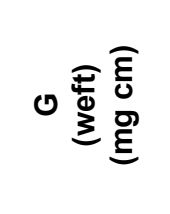 & $\begin{array}{l}0 \\
+1 \\
0 \\
N \\
\ddot{0}\end{array}$ & $\begin{array}{l}0 \\
0 \\
+1 \\
0 \\
0 \\
0 \\
0 \\
0\end{array}$ & 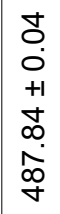 & $\begin{array}{l}5 \\
0 \\
0 \\
+1 \\
1 \\
\infty \\
\infty \\
\infty \\
o \\
o\end{array}$ & $\begin{array}{l}+1 \\
\stackrel{+}{\hat{n}} \\
\stackrel{\sim}{\sim}\end{array}$ & $\begin{array}{l}\bar{\delta} \\
0 \\
+1 \\
o \\
o \\
\tilde{\alpha} \\
\tilde{\alpha} \\
\sigma\end{array}$ & $\begin{array}{l}8 \\
0 \\
0 \\
+1 \\
0 \\
0 \\
0 \\
0 \\
0\end{array}$ & 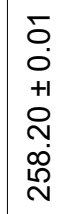 & $\begin{array}{c}0 \\
0 \\
+1 \\
\stackrel{N}{ } \\
\stackrel{m}{N} \\
\stackrel{N}{n}\end{array}$ & $\begin{array}{l}8 \\
0 \\
+1 \\
+1 \\
8 \\
\dot{0} \\
\text { + }\end{array}$ & $\begin{array}{l}8 \\
8 \\
0 \\
+1 \\
o \infty \\
\sim \\
\infty \\
\infty \\
\infty\end{array}$ & $\begin{array}{l}8 \\
0 \\
0 \\
+1 \\
0 \\
0 \\
\dot{\rho} \\
0\end{array}$ & 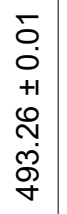 & $\begin{array}{l}\bar{\delta} \\
0 \\
+1 \\
+ \\
\delta \\
\dot{0} \\
\dot{0}\end{array}$ & $\begin{array}{l}8 \\
0 \\
0 \\
+1 \\
0 \\
0 \\
\dot{q} \\
\dot{q}\end{array}$ & $\begin{array}{l}\delta \\
0 \\
0 \\
+1 \\
0 \\
\rho \\
\rho \\
\rho \\
\rho\end{array}$ & $\begin{array}{l}\mathscr{O} \\
0 \\
0 \\
+1 \\
\mathscr{D} \\
0 \\
0 \\
0\end{array}$ & 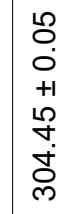 & 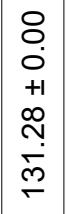 & $\begin{array}{l}\bar{\delta} \\
0 \\
+1 \\
o \\
o \\
o d \\
\tilde{N}\end{array}$ & $\begin{array}{l}8 \\
0 \\
0 \\
+1 \\
m \\
\stackrel{1}{0} \\
\dot{m}\end{array}$ & \\
\hline & 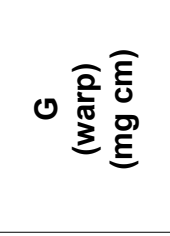 & $\begin{array}{l}\overline{0} \\
0 \\
+1 \\
0 \\
\infty \\
\tilde{p} \\
m\end{array}$ & $\begin{array}{l}\tilde{\delta} \\
0 \\
+1 \\
+1 \\
0 \\
\dot{\sigma} \\
\tilde{m}\end{array}$ & $\begin{array}{l}\delta \\
0 \\
0 \\
+1 \\
0 \\
0 \\
\dot{j} \\
0\end{array}$ & $\begin{array}{l}\tilde{o} \\
0 \\
0 \\
+1 \\
\dot{\alpha} \\
\infty \\
\dot{\alpha} \\
\dot{\alpha}\end{array}$ & $\begin{array}{l}+1 \\
\stackrel{1}{\circ} \\
\stackrel{+}{0}\end{array}$ & $\begin{array}{l}8 \\
0 \\
0 \\
+1 \\
+ \\
0 \\
0 \\
0 \\
0 \\
0 \\
0\end{array}$ & $\begin{array}{l}8 \\
8 \\
0 \\
+1 \\
\infty \\
\infty \\
\dot{\alpha} \\
\dot{j}\end{array}$ & 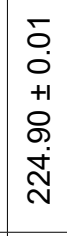 & $\begin{array}{l}8 \\
0 \\
0 \\
+1 \\
\stackrel{+}{\circ} \\
\stackrel{0}{0}\end{array}$ & $\begin{array}{l}8 \\
8 \\
0 \\
+1 \\
+\dot{\alpha} \\
\infty \\
\infty \\
\stackrel{\infty}{\infty}\end{array}$ & $\begin{array}{l}8 \\
0 \\
0 \\
+1 \\
+ \\
\dot{0} \\
\dot{0} \\
\dot{\sigma}\end{array}$ & 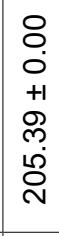 & $\begin{array}{l}\bar{\delta} \\
0 \\
+1 \\
+1 \\
\overline{0} \\
\dot{0} \\
0\end{array}$ & 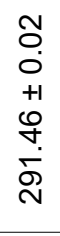 & 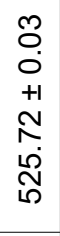 & $\begin{array}{l}\tilde{o} \\
0 \\
0 \\
+1 \\
N \\
\hat{N} \\
\hat{R}\end{array}$ & $\begin{array}{l}8 \\
0 \\
0 \\
+1 \\
\infty \\
\infty \\
\stackrel{N}{N}\end{array}$ & 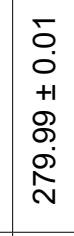 & $\begin{array}{l}\delta \\
0 \\
0 \\
+1 \\
o \\
o \\
\infty \\
\stackrel{f}{f} \\
\end{array}$ & 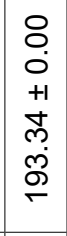 & $\begin{array}{c}\dot{0} \\
+1 \\
+1\end{array}$ & \\
\hline & 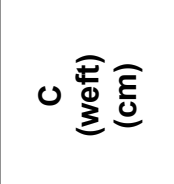 & $\begin{array}{l}\check{c} \\
+1 \\
+1 \\
\infty\end{array}$ & 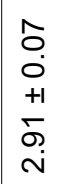 & 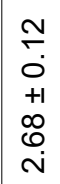 & $\begin{array}{l}\mathscr{O} \\
\dot{0} \\
+1 \\
\stackrel{1}{1} \\
i\end{array}$ & $\begin{array}{l}\hat{0} \\
0 \\
+1 \\
+1\end{array}$ & $\begin{array}{l}\infty \\
0 \\
0 \\
+1 \\
+1 \\
0 \\
0 \\
\infty\end{array}$ & $\begin{array}{l}\dot{y} \\
0 \\
0 \\
+1 \\
\infty \\
\\
\dot{i}\end{array}$ & $\begin{array}{l}\infty \\
\circ \\
0 \\
+1 \\
+1 \\
\\
\text { i }\end{array}$ & $\begin{array}{l}\mathbb{O} \\
\dot{0} \\
+1 \\
\stackrel{1}{0} \\
\stackrel{N}{v}\end{array}$ & 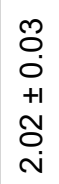 & 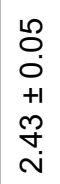 & 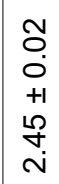 & $\begin{array}{l}\hat{0} \\
0 \\
+1 \\
+1 \\
\& \\
\stackrel{N}{0}\end{array}$ & $\begin{array}{l}\hat{O} \\
0 \\
+1 \\
+ \\
\stackrel{2}{N} \\
\dot{N}\end{array}$ & 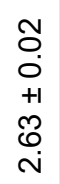 & 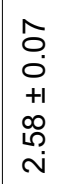 & 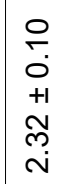 & 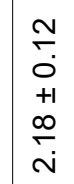 & $\begin{array}{l}0 \\
0 \\
0 \\
+1 \\
\hat{0} \\
\stackrel{-}{-}\end{array}$ & 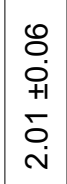 & $\begin{array}{l}P_{-1} \\
\end{array}$ & \\
\hline & 0 产高 & $\stackrel{c}{+}$ & 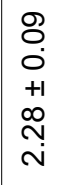 & $\begin{array}{l}\infty \\
0 \\
0 \\
+1 \\
+ \\
\dot{+} \\
\dot{m}\end{array}$ & $\begin{array}{l}\hat{0} \\
0 \\
+ \\
+1 \\
\infty \\
0 \\
\dot{N}\end{array}$ & $\begin{array}{l}0 \\
+1 \\
8 \\
8\end{array}$ & $\begin{array}{l}+ \\
\dot{0} \\
+1 \\
0 \\
0 \\
\infty \\
\dot{n}\end{array}$ & 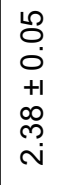 & 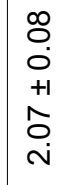 & $\begin{array}{l}0 \\
+1 \\
0 \\
\infty\end{array}$ & $\begin{array}{l}\text { Oo } \\
0 \\
+ \\
+1 \\
\infty \\
0 \\
\stackrel{+}{r}\end{array}$ & 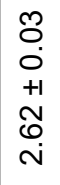 & $\begin{array}{l}n \\
0 \\
0 \\
+1 \\
+1 \\
\alpha \\
-\end{array}$ & $\begin{array}{l}\hat{0} \\
\dot{0} \\
+1 \\
\stackrel{1}{O} \\
\stackrel{N}{v}\end{array}$ & $\begin{array}{l}8 \\
0 \\
0 \\
+1 \\
\text { Dे } \\
\stackrel{n}{N}\end{array}$ & $\begin{array}{l}F \\
\dot{0} \\
+1 \\
\infty \\
\infty \\
\dot{N}\end{array}$ & $\begin{array}{l}8 \\
0 \\
0 \\
+1 \\
\infty \\
\infty \\
\dot{m}\end{array}$ & $\begin{array}{l}0 \\
0 \\
0 \\
+1 \\
\stackrel{1}{\circ} \\
\stackrel{2}{-} \\
\stackrel{-}{-}\end{array}$ & 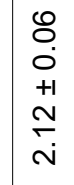 & 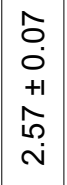 & 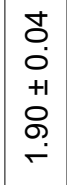 & $\begin{array}{l}0 \\
+1 \\
0 \\
0\end{array}$ & \\
\hline \multicolumn{2}{|c|}{ 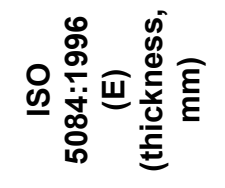 } & \multicolumn{2}{|c|}{$\begin{array}{l}5 \\
0 \\
0 \\
+1 \\
0 \\
0 \\
0\end{array}$} & \multicolumn{2}{|c|}{$\begin{array}{l}5 \\
0 \\
0 \\
+1 \\
0 \\
0 \\
0\end{array}$} & \multicolumn{2}{|c|}{$\begin{array}{l}5 \\
0 \\
0 \\
+1 \\
o \\
o \\
0\end{array}$} & \multicolumn{2}{|c|}{$\begin{array}{l}8 \\
0 \\
0 \\
++1 \\
\infty \\
0 \\
0 \\
0\end{array}$} & \multicolumn{2}{|c|}{$\begin{array}{l}5 \\
0 \\
0 \\
++1 \\
\infty \\
o \\
0 \\
0\end{array}$} & \multicolumn{2}{|c|}{$\begin{array}{l}8 \\
0 \\
0 \\
+1 \\
0 \\
0 \\
0\end{array}$} & \multicolumn{2}{|c|}{$\begin{array}{l}5 \\
0 \\
0 \\
+1 \\
0 \\
0 \\
0 \\
0\end{array}$} & \multicolumn{2}{|c|}{$\begin{array}{l}5 \\
0 \\
0 \\
+1 \\
o \\
o \\
0\end{array}$} & \multicolumn{2}{|c|}{$\begin{array}{l}5 \\
0 \\
0 \\
+1 \\
0 \\
0 \\
0\end{array}$} & \multicolumn{2}{|c|}{$\begin{array}{l}5 \\
0 \\
0 \\
+1 \\
0 \\
0 \\
0\end{array}$} & \multicolumn{2}{|c|}{ 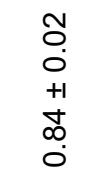 } \\
\hline \multirow{5}{*}{ E } & 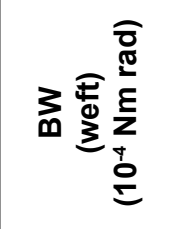 & $\begin{array}{l}8 \\
\dot{0} \\
\dot{+} \\
+1 \\
\hat{+} \\
\infty \\
\infty\end{array}$ & $\begin{array}{l}\stackrel{2}{N} \\
i \\
i \\
+1 \\
N \\
N \\
\end{array}$ & 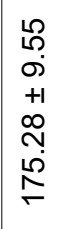 & $\begin{array}{l}\infty \\
\infty \\
\infty \\
+1 \\
+1 \\
\Delta \\
0 \\
\infty \\
\infty \\
-\end{array}$ & $\begin{array}{l}\stackrel{M}{M} \\
\stackrel{5}{\leftarrow} \\
+1 \\
\stackrel{0}{0} \\
0 \\
0\end{array}$ & 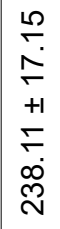 & $\begin{array}{l}0 \\
0 \\
i \\
+1 \\
0 \\
N \\
0 \\
0 \\
m \\
\end{array}$ & 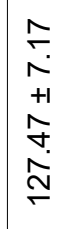 & 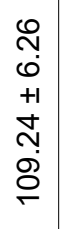 & 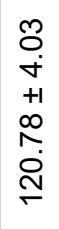 & $\begin{array}{l}\infty \\
0 \\
0 \\
0 \\
+1 \\
8 \\
0 \\
10 \\
\stackrel{0}{0}\end{array}$ & $\begin{array}{l}\infty \\
m \\
\infty \\
+1 \\
+1 \\
0 \\
\stackrel{0}{\rho j} \\
\stackrel{0}{-}\end{array}$ & 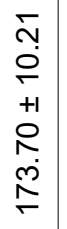 & $\begin{array}{l}0 \\
m \\
+ \\
+1 \\
+1 \\
N \\
\infty \\
\infty \\
\infty\end{array}$ & 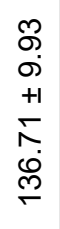 & 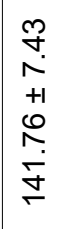 & $\begin{array}{l}\text { No } \\
0 \\
0 \\
+1 \\
+1 \\
\sigma \\
\infty \\
0\end{array}$ & $\begin{array}{l}0 \\
\infty \\
0 \\
0 \\
+1 \\
+1 \\
0 \\
0 \\
0 \\
\end{array}$ & 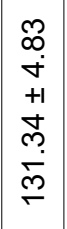 & $\begin{array}{l}8 \\
0 \\
0 \\
+1 \\
0 \\
0 \\
0 \\
\dot{8} \\
\dot{0}\end{array}$ & $\stackrel{\check{+}}{+}$ & \\
\hline & 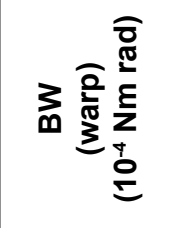 & $\begin{array}{l}0 \\
2 \\
0 \\
+1 \\
+ \\
0 \\
0 \\
\\
\end{array}$ & 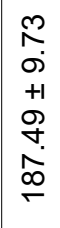 & 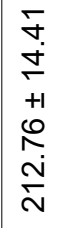 & 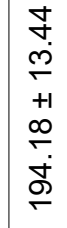 & $\begin{array}{l}0 \\
\infty \\
N \\
+1 \\
0 \\
0\end{array}$ & $\begin{array}{l}+ \\
\infty \\
\infty \\
\sim \\
+1 \\
+1 \\
\infty \\
\infty \\
m \\
m \\
\dot{m}\end{array}$ & $\begin{array}{l}0 \\
0 \\
0 \\
+1 \\
0 \\
0 \\
0 \\
0 \\
\stackrel{0}{0}\end{array}$ & 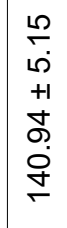 & 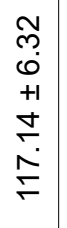 & $\begin{array}{l}\stackrel{L}{0} \\
\dot{+} \\
+1 \\
0 \\
0 \\
\dot{0} \\
\dot{0}\end{array}$ & 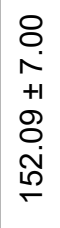 & $\begin{array}{l}0 \\
\infty \\
0 \\
0 \\
+1 \\
0 \\
0 \\
0 \\
0 \\
0\end{array}$ & 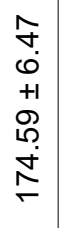 & $\begin{array}{l}\hat{D} \\
+ \\
+1 \\
+ \\
\infty \\
\infty \\
0 \\
\infty\end{array}$ & $\begin{array}{l}\stackrel{i}{N} \\
\stackrel{N}{ } \\
+1 \\
\stackrel{+}{+} \\
\stackrel{N}{\leftarrow}\end{array}$ & 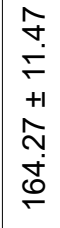 & 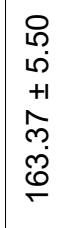 & 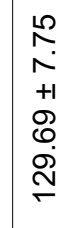 & $\begin{array}{l}0 \\
0 \\
0 \\
+1 \\
+1 \\
0 \\
\dot{0} \\
\infty \\
\sim\end{array}$ & 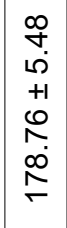 & $\begin{array}{l}+1 \\
0\end{array}$ & ১ \\
\hline & 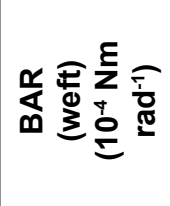 & $\begin{array}{l}+1 \\
\text { t } \\
\sigma\end{array}$ & $\begin{array}{l}\bar{o} \\
\dot{j} \\
+1 \\
\tilde{E} \\
\dot{\sigma}\end{array}$ & $\begin{array}{l}\infty \\
\grave{i} \\
+1 \\
+1 \\
\delta \\
\dot{\Sigma} \\
\grave{N}\end{array}$ & 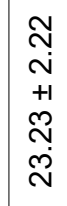 & $\begin{array}{l}5 \\
\stackrel{5}{r} \\
+1 \\
g \\
o\end{array}$ & 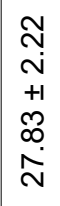 & $\begin{array}{l}\infty \\
\stackrel{\infty}{\sigma} \\
+1 \\
\stackrel{1}{N} \\
\stackrel{0}{r}\end{array}$ & 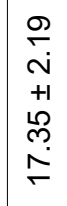 & $\begin{array}{l}\stackrel{\Sigma}{5} \\
\stackrel{+}{+} \\
+1 \\
\stackrel{\sim}{N}\end{array}$ & 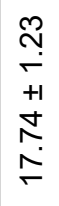 & $\begin{array}{l}\stackrel{O}{i} \\
+1 \\
+1 \\
\stackrel{N}{N} \\
\text { N }\end{array}$ & 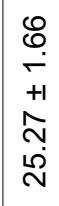 & $\begin{array}{l}\stackrel{m}{\check{c}} \\
\stackrel{+}{+1} \\
\stackrel{m}{m} \\
\stackrel{N}{N}\end{array}$ & 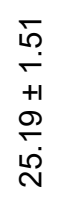 & 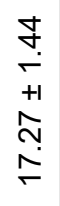 & 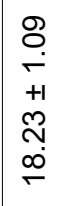 & 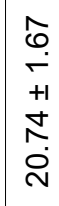 & $\begin{array}{l}\underset{N}{N} \\
\infty \\
+1 \\
\stackrel{1}{2} \\
\stackrel{N}{N}\end{array}$ & 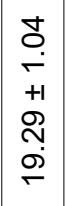 & $\begin{array}{l}m \\
\stackrel{+}{+} \\
+1 \\
\dot{0} \\
\dot{+} \\
\dot{N}\end{array}$ & $\begin{array}{c}- \\
+1 \\
\infty\end{array}$ & $\begin{array}{l}+1 \\
y\end{array}$ \\
\hline & 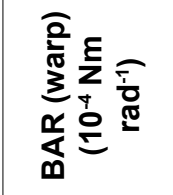 & \begin{tabular}{l}
$\underset{N}{+}$ \\
+1 \\
\multirow{N}{N}{} \\
N
\end{tabular} & $\begin{array}{l}\mathcal{Z} \\
\stackrel{+}{+} \\
++1 \\
\infty \\
\infty\end{array}$ & $\begin{array}{l}0 \\
\infty \\
\dot{\sigma} \\
+1 \\
m \\
m \\
\tilde{N} \\
\dot{v}\end{array}$ & 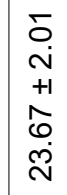 & $\begin{array}{l}\infty \\
\infty \\
i \\
+1 \\
+1\end{array}$ & $\begin{array}{l}\infty \\
m \\
\infty \\
+1 \\
+1 \\
\infty \\
\infty \\
\infty \\
\infty\end{array}$ & 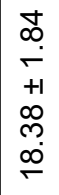 & 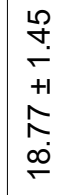 & $\begin{array}{l}\infty \\
0 \\
0 \\
+1 \\
+1\end{array}$ & 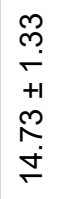 & 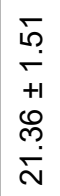 & 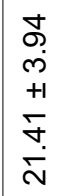 & $\begin{array}{l}\hat{N} \\
\stackrel{+}{+} \\
+1 \\
\stackrel{\rho}{m} \\
\end{array}$ & 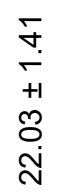 & 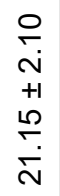 & 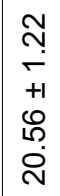 & $\frac{\sigma_{r}}{+}$ & $\begin{array}{l}\tilde{T} \\
\mathfrak{N} \\
+1 \\
\stackrel{N}{N} \\
\infty \\
\stackrel{\infty}{\sim}\end{array}$ & $\mid \begin{array}{c}\infty \\
\stackrel{\infty}{+} \\
\stackrel{+}{+1} \\
\stackrel{N}{\sim} \\
\stackrel{\rho}{N}\end{array}$ & 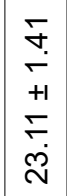 & $\stackrel{+}{+1}$ & $\begin{array}{l}+ \\
+ \\
0 \\
i \\
0\end{array}$ \\
\hline & 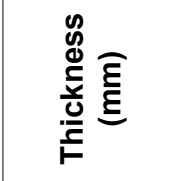 & $\begin{array}{l}0 \\
0 \\
+1 \\
+1 \\
0\end{array}$ & \begin{tabular}{l}
$\tilde{c}$ \\
0 \\
0 \\
+1 \\
\multirow{+}{*}{}
\end{tabular} & $\begin{array}{l}0 \\
0 \\
0 \\
+1 \\
0 \\
0 \\
0 \\
0\end{array}$ & $\begin{array}{l}0 \\
0 \\
+1 \\
0 \\
0 \\
0 \\
0\end{array}$ & $\begin{array}{l}0 \\
0 \\
+1 \\
+1\end{array}$ & $\begin{array}{l}\tilde{O} \\
0 \\
0 \\
+1 \\
0 \\
0\end{array}$ & \begin{tabular}{l}
$\tilde{O}$ \\
0 \\
0 \\
+1 \\
+1 \\
\multirow{5}{0}{} \\
0
\end{tabular} & 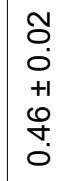 & $\begin{array}{l}\text { Oे } \\
0 \\
0 \\
+1 \\
0\end{array}$ & $\begin{array}{l}\tilde{O} \\
0 \\
0 \\
+1 \\
\end{array}$ & $\begin{array}{l}0 \\
0 \\
0 \\
+1 \\
0 \\
0 \\
0 \\
0\end{array}$ & $\begin{array}{l}0 \\
0 \\
0 \\
+1 \\
0 \\
0 \\
0\end{array}$ & \begin{tabular}{c} 
oे \\
0 \\
0 \\
+1 \\
$o$ \\
\multirow{g}{0}{} \\
0
\end{tabular} & $\begin{array}{l}\text { O } \\
0 \\
0 \\
+1 \\
0 \\
0 \\
0 \\
0\end{array}$ & $\begin{array}{l}0 \\
0 \\
0 \\
+1 \\
10 \\
0 \\
0\end{array}$ & $\begin{array}{l}3 \\
0 \\
0 \\
+1 \\
0 \\
0 \\
0 \\
0\end{array}$ & $\begin{array}{l}5 \\
0 \\
0 \\
+1 \\
0\end{array}$ & $\begin{array}{l}5 \\
0 \\
0 \\
+1 \\
o \\
+ \\
0\end{array}$ & $\begin{array}{l}\delta \\
0 \\
0 \\
+1 \\
\dot{+} \\
0 \\
0\end{array}$ & $\begin{array}{l}\delta \\
0 \\
+1 \\
0 \\
0 \\
0\end{array}$ & $\begin{array}{l}0 \\
+1\end{array}$ & 0 \\
\hline & $\frac{0}{0}$ & $\tau$ & $\frac{\mathscr{0}}{\frac{0}{0}}$ & $\frac{10}{90}$ & $\begin{array}{l}\frac{0}{0} \\
\frac{0}{50} \\
\frac{0}{0}\end{array}$ & $\frac{0}{\frac{0}{0}}$ & 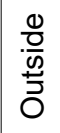 & $\begin{array}{l}\frac{0}{.0} \\
\frac{0}{0} \\
\underline{=}\end{array}$ & $\begin{array}{l}\frac{0}{0} \\
\frac{0}{50} \\
\frac{0}{0}\end{array}$ & $\begin{array}{l}\frac{0}{0} \\
\frac{0}{6} \\
\underline{\underline{E}}\end{array}$ & $\frac{0}{\frac{0}{0}}$ & 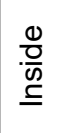 & $\begin{array}{l}\frac{0}{0} \\
\frac{0}{5} \\
\frac{10}{0}\end{array}$ & $\frac{\stackrel{0}{0}}{9}$ & $\begin{array}{l}\frac{0}{0} \\
\frac{0}{50} \\
50 \\
0\end{array}$ & $\frac{0}{.0}$ & $\begin{array}{l}\frac{0}{0} \\
\frac{0}{90} \\
\frac{9}{5} \\
0\end{array}$ & $\frac{\frac{0}{0}}{9}$ & $\begin{array}{l}\frac{0}{\frac{0}{0}} \\
\frac{10}{50} \\
0\end{array}$ & $\begin{array}{l}\frac{0}{.0} \\
\frac{0}{0} \\
\underline{\underline{D}}\end{array}$ & $\begin{array}{l}\frac{0}{0} \\
\frac{0}{5} \\
0\end{array}$ & $\underline{\underline{5}}$ & \\
\hline & $\begin{array}{l}\frac{0}{5} \\
\frac{0}{\pi} \\
\frac{\pi}{\pi}\end{array}$ & & & & Ф & 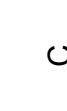 & & & $\boldsymbol{s}$ & 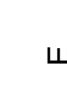 & & & & 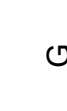 & & 1 & & & & & & & \\
\hline
\end{tabular}


amount of material being bent is constant. This allows to obtain the BW as an integration of the forces, and the BAR as a slope of the measured forces. Comparing the correlations calculated between the indices from FTT and standard method, it can be observed that BW has a better correlation than BAR with the parameters obtained from the standard method. However, as highlighted in Table 4, BW correlates best with MC (mass of the fabric multiplied by its bending length) in two cases, while it correlates best with MCC (mass of the fabric multiplied by its squared bending length) in one case (and twice close to the MC result), and also once with $G$. Nevertheless, if the overall data is considered, BW is best correlated with MCC. We conclude that BW correlates best with the standard measurement, and specifically with the MCC value.

The best correlation of BW with MCC can be explained as follows. The formula for $G$ is $0.1 \times M X C^{3}$, so $M C C$ is actually reducing the power of $C$ from 3 to 2 . Since bending moment $B$ is also regarded as flexural rigidity $G$ times the curvature $(B=G k)$, where $k$ is the curvature given by $1 / R$, with $R$ being the radius of the circle from where the bending curvature is formed. In a first order approximation, $\mathrm{R}$ can be considered proportional with $\mathrm{C}$, so $R \approx a \mathrm{C}$, and hence $\mathrm{B} \approx \mathrm{G} /(\mathrm{a} \mathrm{C})$. The bending work $B W$ in the FTT, on the other hand, is the average bending moment over all radians sampled by the FTT. As a consequence, the good correlation between BW and MCC is not unexpected. Figure 9 shows a scatter plot and the regression model of relationship between the overall BW and MCC. Coefficient of determination $\mathrm{R}^{2}=0.83$ demonstrates a strong fitting of the data towards the model and from that, yields 0.91 as Pearson correlation value, which proves a very good correlation between $\mathrm{BW}$ and MCC. The regression model MCC $=1.1194 \mathrm{BW}-266.1$ has an intercept at MCC at -266.1 , which might have contributed to the given device tolerance of $\pm 10 \%$ for the FTT. We conclude that three closely related indices, MC, MCC and G, have a good relationship with BAR and BW, with just small Pearson's correlation r-value differences between them. Amongst all, MCC gives the best correlation for the overall data set with BW.

On a side note, the BAR derivation in the reference from the manufacturer is mathematically not so well defined. Although it still gives a very strong correlation with other indices, this is because of the strong correlation with $\mathrm{BW}$, which reduces the usefulness of BAR as a separate FTT parameter. It should however relate to the speed to which the bending moment

Table 4. The Pearson's correlation values for outside and inside warp and weft bending parameters of the tested fabrics

\begin{tabular}{|c|c|c|c|c|c|c|}
\hline \multicolumn{7}{|c|}{ Outside warp } \\
\hline & BAR & BW & $\mathrm{C}$ & $\mathrm{MC}$ & MCC & G \\
\hline BAR & $x$ & 0.99 & 0.78 & 0.86 & 0.84 & 0.82 \\
\hline BW & - & $X$ & 0.82 & 0.89 & 0.87 & 0.84 \\
\hline C & - & - & $x$ & $x$ & $x$ & 0.99 \\
\hline \multicolumn{7}{|c|}{ Inside warp } \\
\hline & BAR & BW & C & $\mathrm{MC}$ & MCC & G \\
\hline BAR & $x$ & 0.98 & 0.82 & 0.77 & 0.85 & 0.88 \\
\hline BW & - & $x$ & 0.91 & 0.84 & 0.92 & 0.94 \\
\hline C & - & - & $x$ & $x$ & $x$ & 0.94 \\
\hline \multicolumn{7}{|c|}{ Outside weft } \\
\hline & BAR & BW & C & $\mathrm{MC}$ & MCC & G \\
\hline BAR & $x$ & 0.93 & 0.82 & 0.92 & 0.86 & 0.77 \\
\hline BW & - & $x$ & 0.93 & 0.96 & 0.96 & 0.90 \\
\hline C & - & - & $x$ & $x$ & $x$ & 0.93 \\
\hline \multicolumn{7}{|c|}{ Inside weft } \\
\hline & BAR & BW & C & $\mathrm{MC}$ & MCC & G \\
\hline BAR & $x$ & 0.96 & 0.87 & 0.93 & 0.91 & 0.86 \\
\hline BW & - & $x$ & 0.92 & 0.95 & 0.96 & 0.93 \\
\hline C & - & - & $x$ & $x$ & $x$ & 0.97 \\
\hline
\end{tabular}

${ }^{*} \mathrm{X}$ : non-relevant correlation ${ }^{* *}$ - correlation is already stated in other cells

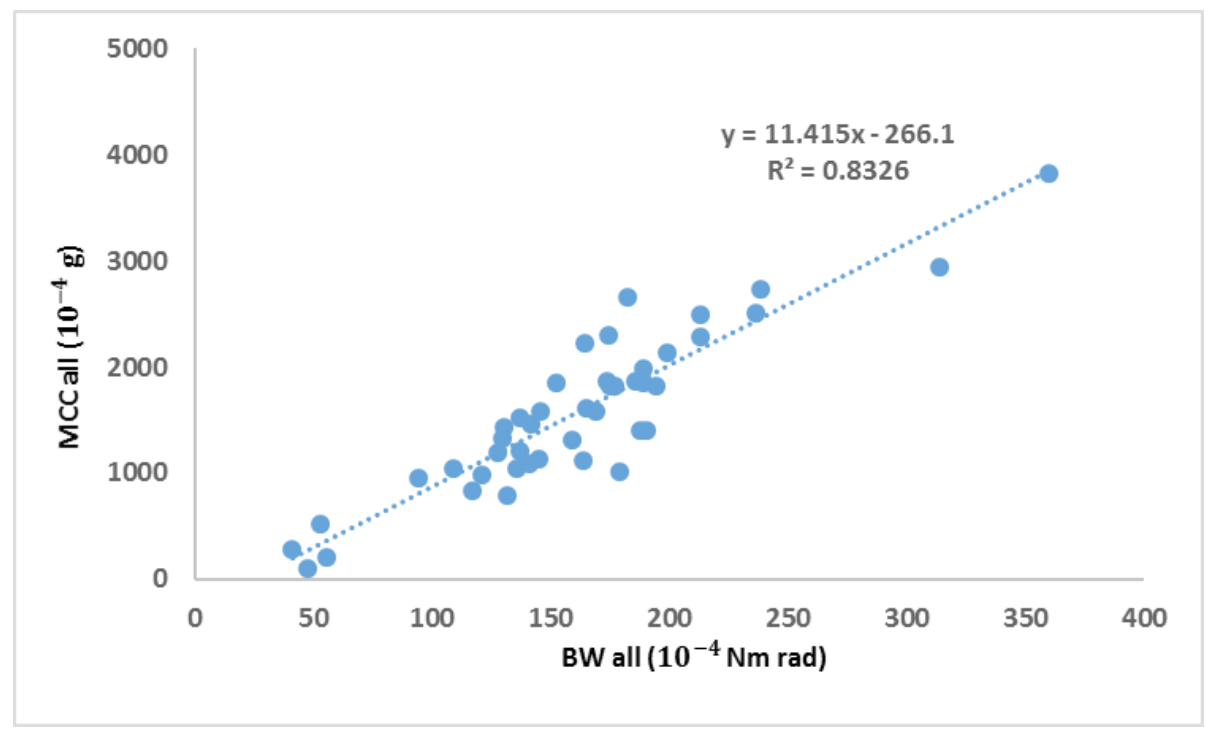

Figure 9. Correlation between the overall BW and MCC 
increases, as the sample bends more. Therefore, as a suggestion, it might be useful to have an automated bending tester that can measure the bending length in terms of the angle as an extension to the BS 3356-1990 standard. The speed of the bending length change should then in turn relate to the rigidity of the samples against bending. Thus, it would be possible to draw a better conclusion from the phenomenon underlying the principle of BAR.

\section{Conclusions}

A new equipment from SDL Atlas, the FTT, offers a new way of computing hand and touch sensations of fabrics. The bending module and thickness measurement were analyzed and compared with the standard methods that are commonly used in the textile industry, in order to gain a better understanding on how they relate and if the FTT can be used as an alternative. This will reduce the testing and computing time for the companies having an FTT in their lab. 11 fabrics with different fiber composition and construction type were tested using FTT and standard methods for thickness and bending. Despite having differences in the principle of measurement, it is found that FTT demonstrates a significant correlation with the standard methods. The Pearson's correlation, $r$ gives 0.97 for thickness while for bending, in overall, BW shows the highest correlation with MCC, which is at 0.91 for the overall value from warp and weft samples. The correlation analysis indicates a very strong correlation between FTT and standard methods for thickness and bending. The findings are significant as to estimate the reliability and comparability of the FTT towards the standard measurements, within the said scope and limitation. For the thickness measurement, although the correlation is high, FTT should not be used as an alternative measure at the moment. A standard calibration method of the FTT would be required, and the compression measurement at $1 \mathrm{kPA}$ should be used instead of the value at $4.018 \mathrm{kPA}$

\section{ACKNOWLEDGEMENTS}

This work is a part of a doctoral research finding, hence the author would like to acknowledge Ministry of Education, Malaysia and Universiti Teknologi MARA, Malaysia for the sponsorship given for the study. The materials were received from Sioen Industries, Belgium and the results are obtained within an international ERANET-CORNET research project IWT 140387 (2015-2016) named Touché: Boosting innovation through application of basic understanding of the process and testing of textile touch and fabric feel.

\section{References}

[1] S. Chen, S. Ge, W. Tang, J. Zhang, and N. Chen, "Tactile perception of fabrics with an artificial finger compared to human sensing," Text. Res. J., vol. 85, no. 20, pp. 2177-2187, 2015.

[2] K. O. Johnson, "The roles and functions of cutaneous mechanoreceptors," Curr. Opin. Neurobiol., vol. 11, no. 4, pp. 455-461, 2001.
[3] N. Nawaz, O. Troynikov, and C. Watson, "Evaluation of surface characteristics of fabrics suitable for skin layer of firefighters' protective clothing," Phys. Procedia, vol. 22, pp. 478-486, 2011.

[4] M. N. Sun, "A New Tester and Method for Measuring Fabric Stiffness and Drape," Text. Res. J., vol. 78, no. 9, pp. 761-770, 2008.

[5] E. Strazdiene, G. Martisiute, M. Gutauskas, and L. Papreckiene, "Textile Hand: A New Method for Textile Objective Evaluation," J. Text. Inst., no. 94:3-4, pp. 245255, 2003.

[6] J. Hu, "Characterization of Sensory Comfort of Apparel Products," The Hong Kong Polytechnic University, 2006.

[7] I. L. Ciesielska-Wrobel, L. Van Langenhove, and K. Grabowska, "Fingertip skin models for analysis of the haptic perception of textiles," J. Biomed. Sci. Eng., vol. 7, no. 1, pp. 1-6, 2014.

[8] J. Z. Wu, R. G. Dong, S. Rakheja, A. W. Schopper, and W. $P$. Smutz, "A structural fingertip model for simulating of the biomechanics of tactile sensation," Med. Eng. Phys., vol. 26, no. 2, pp. 165-175, 2004.

[9] M. M. Q. Xing, Z. Sun, N. Pan, W. Zhong, and H. I. Maibach, "An EFE model on skin-sleeve interactions during arm rotation," J. Biomech. Eng., vol. 128, no. 6, pp. 872-878, 2006.

[10] I. L. Ciesielska-Wrobel and L. Van Langenhove, "The hand of textiles - definitions, achievements, perspectives - a review," Text. Res. J., vol. 82, no. 14, pp. 1457-1468, 2012.

[11] H. Yokura and M. Niwa, "Objective hand measurement of nonwoven fabrics used for the top sheets of dis ...," Text. Res. J., 2003.

[12] M. Inoue and S. Kurata, "Theoretical analysis of compression properties of blankets," Int. J., vol. 14, no. 3, pp. 216-222, 2002.

[13]H. M.Behery, Ed., Effect of mechanical and physical properties on fabric hand. Cambridge, England: woodhead publishing limited, 2005.

[14] A. De Boos and David Tester, "SiroFAST Fabric Assurance by Simple Testing," 1994.

[15] J. Y. Hu, L. Hes, Y. Li, K. W. Yeung, and B. G. Yao, "Fabric Touch Tester: Integrated evaluation of thermal-mechanical sensory properties of polymeric materials," Polym. Test., vol. 25, no. 8, pp. 1081-1090, 2006.

[16]X.-X. Wu, Y. Li, J. Y. Hu, X. Liao, and Q.-H. Li, "A Comparative Study of Fabric Stiffness Based on FTT, KES and Subjective Testing," in TEXTILE BIOENGINEERING AND INFORMATICS SYMPOSIUM PROCEEDINGS, 2013, pp. 1147-1154.

[17] X. Liao, Y. Li, J. Hu, X. Wu, and Q. Li, "A simultaneous measurement method to characterize touch properties of textile materials," Fibers Polym., vol. 15, no. 7, pp. 15481559, 2014.

[18]X. Liao, Y. Li, J. Hu, Q. Li, and X. Wu, "Psychophysical Relations between Interacted Fabric Thermal-Tactile Properties and Psychological Touch Perceptions," J. Sens. Stud., vol. 31, no. 3, pp. 181-192, 2016.

[19] S. Vasile, B. Malengier, A. De Raeve, J. Louwagie, and M. Vanderhoeven, "Assessment of sensorial comfort of fabrics for protective clothing," in 7th European Conference on Protective Clothing ECPC, 2016. 
[20] K. L. Hatch, S. Francisco, R. L. Barker, S. S. Woo, P. Radhakrishnaiah, and N. Carolina, "In Vivo Cutaneous and Perceived Comfort Response to Fabric Part I: Thermophysiological Comfort Determinations for Three Experimental Knit Fabrics," Text. Res. J., vol. 60, no. 7, pp. 405-412, 1990.

[21] U. R. Amrit, "Bedding textiles and their influence on thermal comfort and sleep," Autex Res. J., vol. 7, no. 4, pp. 252254, 2007.

[22] M. Kocik, W. Zurek, I. Krucinska, J. Gersak, and J. Jakubczyk, "Evaluating the bending rigidity of flat textiles with the use of an instron tensile tester," Fibres Text. East. Eur., vol. 13, no. 2, pp. 31-34, 2005.
[23] K. Kim, M. Takatera, and C. Sugiyama, "Relationship between jacket comfort and stiffness of adhesive interlining," in PROCEEDING OF INTERNATIONAL CONFERENCE ON KANSEI ENGINEERING AND EMOTION RESEARCH (KEER2014), 2014, pp. 779-787.

[24] SDL Atlas and Rycobel, "Fabric Touch Tester, Instruction Manual." SDL Atlas, 2014.

[25] European Committee for Standardization, "TextilesDetermination of thickness of textiles and textile products (ISO 5084:1996)." Brussels, pp. 1-5, 1996.

[26] British Standard Institution, "Determination of stiffness of cloth (BS 3356:1990)." 1990.

[27] F. T. Peirce, "The handle of cloth as a measurable quality," J. Text. Inst., 1930. 